Aim of the study: It is estimated that between $15 \%$ and $35 \%$ of sporadic colorectal cancers (CRC) developing from adenomas come from serrated polyps. Currently, the most effective method used to prevent CRC is the removal of adenomas, including serrated polyps, during colonoscopy. The aim of this paper is to analyze the changes characterized as serrated polyps and detected during screening colonoscopies performed as part of the Screening Program for Early Colorectal Cancer Detection (SPED).

Material and methods: In our center, as part of the nationwide SPED between 2000 and 2009, 1,442 screening colonoscopies were performed.

Results: Serrated polyps were found in $11.9 \%$ of all patients and in $45.8 \%$ of patients who had polyps removed by endoscopy. In screening colonoscopy of the large intestine, the following polyps were found most frequently: hyperplastic, $<1 \mathrm{~cm}$, without a stalk, multiple, located in the distal part of the large intestine, in men and in patients with a first-degree relative with a history of abdominal cancer. Detecting and removing polyps was facilitated by the fact that the cecum was intubated and the bowel preparation had been performed either very well or well. The detection rate of serrated polyps was not influenced by patients place of residence or their age.

Conclusions: Serrated polyps constitute a frequent, and very frequent among removed polyps, abnormality detected during screening colonoscopy.

Key words: colorectal cancer, screening colonoscopy, serrated polyps, adenomas.

Contemp Oncol (Pozn) 2014; 18 (1): 54-59 DOI: $10.5114 /$ wo.2014.40435

\section{Serrated polyps detected during screening colonoscopies}

\author{
Maciej Świątkowski ${ }^{1}$, Agnieszka Meder ${ }^{1}$, Lesław Sobczyński ${ }^{1}$, Jarosław Koza ${ }^{1}$, \\ Małgorzata Szamocka', Janina Brudny ${ }^{1}$, Jadwiga Korenkiewicz ${ }^{2}$
}

${ }^{1}$ Chair and Department of Gastroenterology, Vascular and Internal Diseases, Nicolaus Copernicus University, Ludwik Rydygier Collegium Medicum in Bydgoszcz, Poland 2Division of Pathomorphology, Dr Jan Biziel University Hospital No. 2 in Bydgoszcz, Poland

\section{Introduction}

Epithelial polyps are the most frequent precursors of colorectal cancer. Carcinogenesis of epithelial polyps in CRC is a process consisting of many stages and lasting a number of years, and only a small number of polyps undergo a malignant transformation during their course [1]. The development of the cancer results from progressive genetic (most frequently mutations) and epigenetic disorders in the form of changes in gene expression resulting from the modification of chromatin structure, but without changes in the DNA sequence [2]. Among the initial stages in the development of proliferous and dysplastic changes in the large intestine there are small foci that are invisible in endoscopy using dyes and magnifying techniques, referred to as aberrant crypt foci (ACF). Aberrant crypt foci with the characteristics of hyperplastic and dysplastic polyps are listed in the histological classification of digestive tract tumors prepared by the WHO in 2000. The mixed form composed of both hyperplastic and dysplastic crypts is also described there [3]. Besides the theory of carcinogenesis in the large intestine as the process of adenomas changing into tumors, which has been acknowledged for several dozen years, another pathogenetic form of sporadic CRC development has been found [4-7]. Hyperplastic polyps belong to those most frequently found in the large intestine. They are usually small, located in the rectum or sigmoid colon, and unimportant as regards malignant transformation. Their section has a serrated structure because of the varying height of the over-mature epithelium that lines them [8]. On the other hand, serrated adenomas have the characteristics of both hyperplastic polyps and adenomas. Macroscopically they take a different morphological form in the large intestine, ranging from convex with a wide base located mainly in the rectum or sigmoid to slightly raised and flat and most often found in the colon. They occur as single or multiple adenomas and are seldom larger than $1 \mathrm{~cm}$ in diameter [9]. As far as histology is concerned, serrated adenomas combine the architectonic changes of hyperplastic polyps with the basic cytological features of adenomatous dysplasia, recently called endoepithelial neoplasia [10]. The research into serrated adenomas conducted in the last decade has shown, when considering their molecular structure, that they are characterized by mutation of the BRAF gene and accompanying microsatellite instability, whereas as far as morphology is concerned, a few histological varieties have been distinguished [11-13]. A traditional serrated adenoma retains the characteristics of the serrated ducts of dysplastic glands. A mixed polyp has a structure typical of a hyperplastic polyp and an adenoma. A sessile serrated polyp is a special variety because it has the greatest danger of malignant transformation $[6,14,15]$. This macroscopic change is of a flat type that differs from a hyperplastic polyp in the irregular system of the lower part of its gland ducts and the presence of mitoses that are also found in the middle and upper parts of the ducts. All these varieties currently form the group 
of serrated polyps [16]. Hyperplastic polyposis syndrome is an example of multiple hyperplastic polyps. This syndrome is not genetically conditioned and may take part in CRC pathogenesis [17]. The carcinogenesis from hyperplastic ACF through serrated adenoma or a mixed polyp with dysplasia to CRC is responsible for the sporadic cancer formation in $15 \%$ of cases [18]. The prevalence of serrated polyps in the total polyps group found in colonoscopy is estimated to range from $10 \%$ to $40 \%$ [19-21]. The aim of this paper is to analyze the changes characterized as serrated polyps and detected during screening colonoscopies performed as part of the Screening Program for Early Colorectal Cancer Detection in the period 2000-2009.

\section{Material and methods}

The analysis was performed between 2000 and 2009 at the Endoscopy Unit of the Gastrointestinal Tract of the Gastroenterology, Vascular Diseases and Internal Diseases Department of Nicolaus Copernicus University in Toruń, Collegium Medicum in Bydgoszcz based in University Hospital No. 2 in Bydgoszcz as part of the Screening Program for Early Colorectal Cancer Detection financed by the Polish Ministry of Health. Polish citizens aged 50-65 or 40-65 with a history of abdominal cancer in a first-degree relative took part in the analysis. The criteria for exclusion from the program were as follows: the presence of clinical symptoms suggesting CRC, serious disease, an earlier diagnosis of inflammatory bowel diseases, and familial adenomatous polyposis or hereditary cancer unrelated to polyposis. After talking with the doctor and completing a questionnaire, the patients signed their consent to the examination. The day before the examination patients took an agent based on polyethylene glycol (Fortrans in a dose of $296 \mathrm{~g}$ ) dissolved in water (4 liters). Most examinations were performed under anesthesia with the sedative midazolam $(7.5 \mathrm{mg})$. The sedative was administered orally in the form of a pill 15 minutes before the examination. The doctor performing the screening colonoscopy described cecum availability, all abnormalities encountered, and the quality of the bowel preparation. The quality of the large intestine cleansing was assessed using the 4-de-

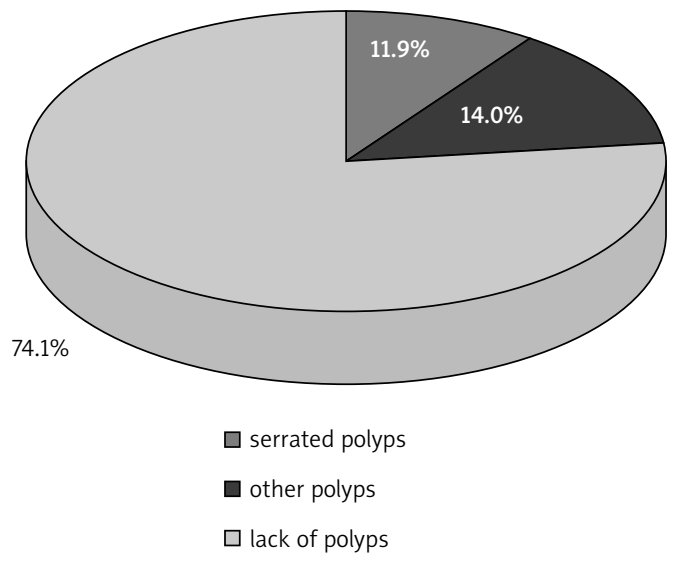

Fig. 1. Prevalence of polyps detected during screening colonoscopy gree scale proposed by the American Society of Gastrointestinal Endoscopy (ASGE) and the American College of Gastroenterology: very good, good, sufficient, and poor cleansing [22]. During the screening colonoscopy, polyps of any size up to $1 \mathrm{~cm}$ were removed. Histopathological examinations were carried out by one pathomorphology specialist at the Pathomorphology Department of University Hospital No. 2 over the whole 10-year period of the Screening Program for Early Colorectal Cancer Detection. Histopathological evaluation was based on the criteria set by the World Health Organization. Larger polyps were removed separately under hospital conditions.

Fisher's exact test was used for the statistical evaluation of the data. A value of $p<0.05$ was assumed to be statistically significant.

\section{Results}

Colonoscopies as part of the Screening Program for Early Colorectal Cancer Detection between 2000 and 2009 were performed on 1,442 people. During their colonoscopy 373 patients (25.9\%) had polyps removed, including 171 people with serrated polyps. They constituted $11.9 \%$ of the whole analysis group and $45.8 \%$ of the people who underwent a polypectomy (Fig. 1). Serrated polyps had a histopathological structure of hyperplastic polyps in 107 patients (7.4\% of the whole research group) and of a serrated adenoma in 64 (4.4\% of the whole research group). The synchronous presence of a hyperplastic polyp and serrated adenoma was found in 10 of the patients. Among the analysis participants with serrated polyps there were 89 women (10.1\% of the women from the analysis group) and 82 men (14.7\% of all the men taking part in the analysis) and this difference was statistically significant ( $p=0.0095$; Fig. 2). Among the participants from that group there were $134(12.7 \%)$ people living in cities with a population of more than 300,000, 17 (8.1\%) in cities with a smaller population and $20(11.1 \%)$ living in rural areas (Fig. 3). The average age of people with serrated polyps was 55.7 years, including 55.9 for women and 55.4 for men. There were 11 (9.1\%) patients aged 40-49, 119 (12.9\%) aged 50-59 and 41 (10.2\%) aged 60-65 (Fig. 4). Fifty-seven of the analysis participants

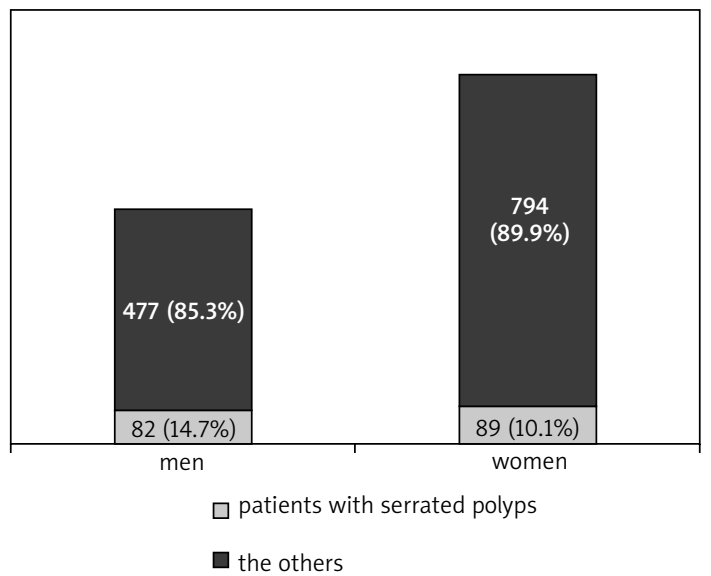

Fig. 2. Serrated polyps in relation to the gender of the participants $(p=0.0095)$ 


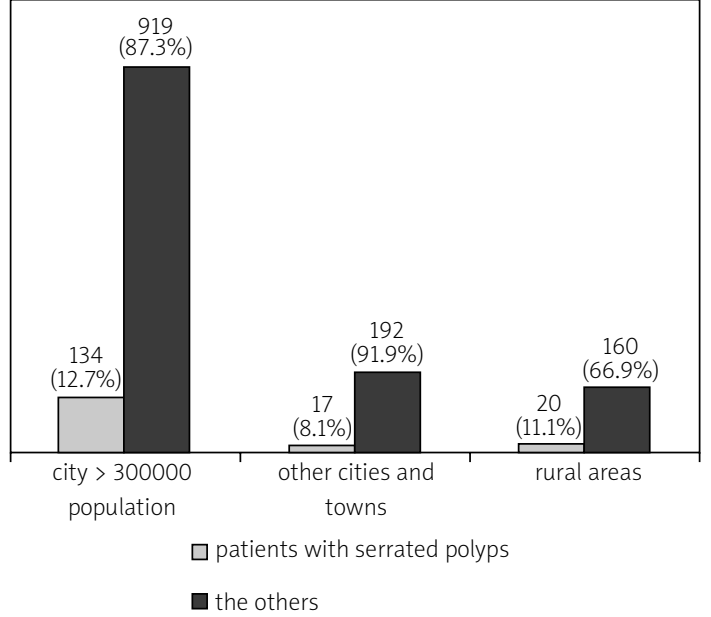

Fig. 3. Serrated polyps and place of residence

(33.3\%) informed us about having other diseases, mainly arterial hypertension, coronary artery disease, cholelithiasis and thyroid disorders, and 78 had a first-degree relative who had been diagnosed with abdominal cancer (gastric, hepatic or colorectal). Serrated polyps were much more common among patients with a first-degree relative ("Positive") with abdominal cancer ( $p<0.0001$; Fig. 5). Intubation of the cecum was achieved in $96.5 \%$ of cases. Endoscopists evaluated the intestine as having been very well prepared for the examination in 110 cases (64.3\%), well prepared in 54 cases (31.6\%) and satisfactorily prepared in 7 cases (4.1\%). Screening colonoscopies were performed under anesthesia in 153 patients (89.5\%) and without an anesthetic in 18 patients (10.5\%) with confirmed serrated polyps. Among patients with serrated polyps a single polyp was detected in 65 people (38\%), a few polyps ( $2-4$ polyps) in 52 people (30.4\%) and more than five polyps in 54 people (31.6\%) (Fig. 6). Serrated polyps were located only in the rectum and sigmoid colon in 110 patients (64.3\%), only in the proximal part in 30 patients (17.6\%) and synchronously

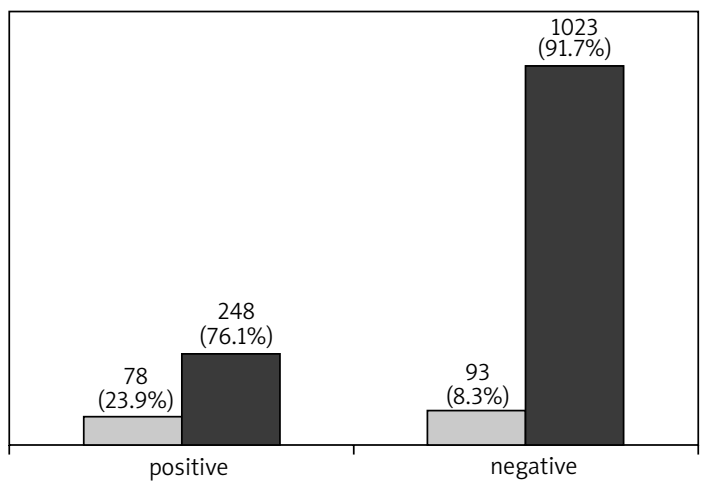

$\square$ with serrated polyps

$\square$ without serrated polyps

Fig. 5. Participants with a first-degree relative diagnosed with abdominal cancer ("Positive") and without ("Negative") in relation to serrated polyps $(p<0.0001)$

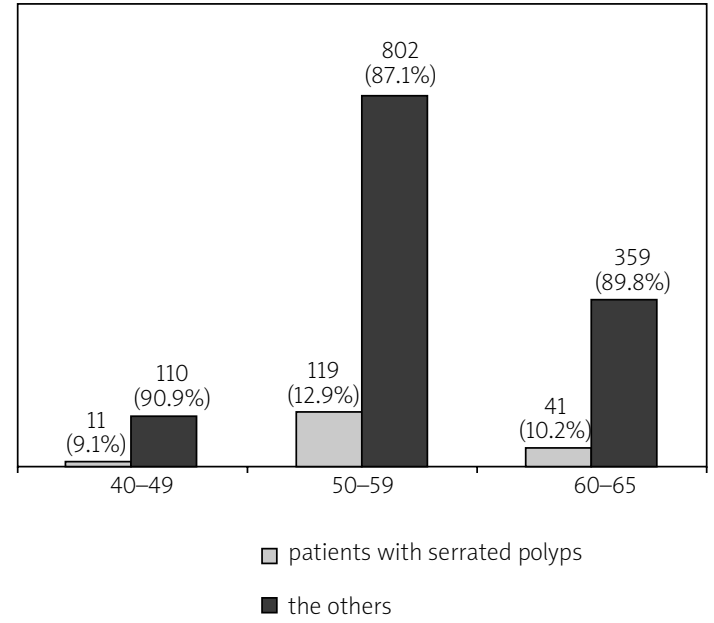

Fig. 4. Serrated polyps in relation to the age of the participants

in the proximal and distal parts in 31 patients (18.1\%) (Fig. 7). Stalked serrated polyps were detected in 52 analysis participants (30.4\%), whereas semi-stalked and flat polyps were found in 119 participants (69.6\%) (Fig. 8). The polyps were larger than $1 \mathrm{~cm}$ in 29 patients (17\%), between 5 and $10 \mathrm{~mm}$ in 50 patients (29.2\%) and smaller than $5 \mathrm{~mm}$ in 92 patients (53.8\%) (Fig. 9). The results of polyp size analysis in relation to gender are presented in Table 1. Five-millimeter and bigger polyps were more often found in men ( $p<$ 0.0001). The most frequent additional abnormality found during colonoscopy was diverticula, which were found in 38 participants $(22.2 \%)$ with confirmed serrated polyps, whilst hemorrhoids were detected in 36 patients (21.1\%). A histopathological examination of the serrated polyps indicated that two had a mixed structure of a hyperplastic polyp and a tubular adenoma, and another that of a serrated adenoma and a villous adenoma. Tubular and tubulovillous adenomas occurred simultaneously in 27 cases (15.8\%) and a villous adenoma in one case. There were two people (1.2\%) with serrated adenomas larger than $10 \mathrm{~mm}$

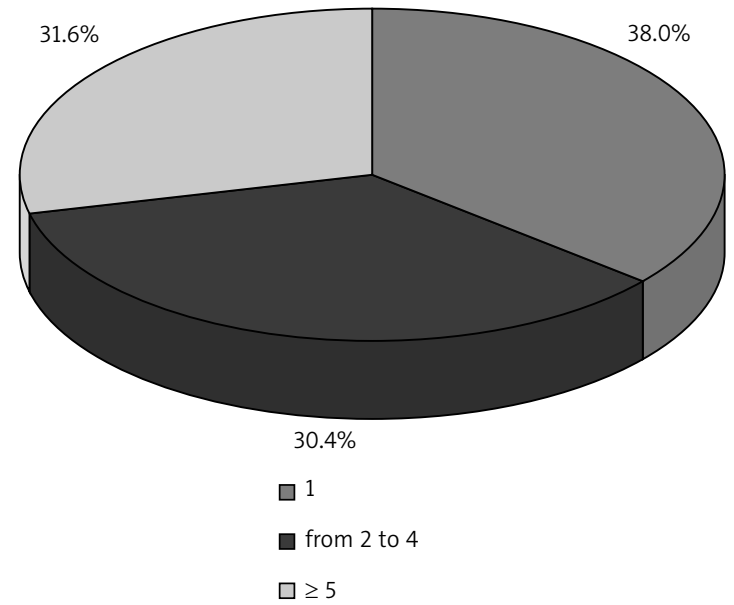

Fig. 6. Number of serrated polyps in patients 


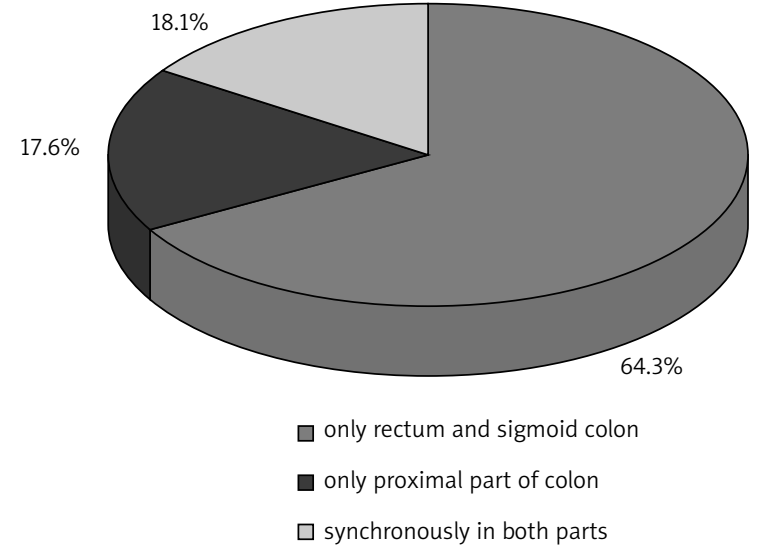

Fig. 7. Location of the serrated polyps found in patients

in whom other adenomas, hyperplastic polyps or cancers occurred simultaneously. In one case cancer was located in the rectum, in the second case in the transverse colon.

\section{Discussion}

Serrated polyps are abnormalities that are frequently found in the large intestine during diagnostic screening colonoscopies. They were found in every eighth person in our analysis and in almost 50\% of the patients who had polyps removed during colonoscopy. The results obtained in our analysis confirm the observation of other researchers claiming that serrated adenomas are detected during screening colonoscopy as frequently as conventional adenomas [23]. Women came forward more frequently than men for a screening colonoscopy carried out in our center. However, serrated polyps were statistically significantly more frequently detected in men than in women [24]. Many publications suggest that CRC based on polyps, including serrated polyps, occur with the same frequency in both men and women [25]. In 2008 in Kujawsko-Pomorskie province 459 men and 386 women were registered as having been diagnosed with CRC. The analysis of the CRC incidence register indicates that between 2001 and 2008 in the Kujawsko-Pomorskie region the number of CRC cases increased every year and that each year there were more and more men than women registered as having been diagnosed with CRC $[26,27]$. Another paper indicates that traditional adenomas, being the most frequent pre-cancer conditions in the large intestine, occurred more frequently in men than in women, with a statistically significant difference [28]. That analysis suggests that men ought to be encouraged to attend screenings as they, either at their doctor's prompting or spontaneously, come forward for screening tests less frequently than women $[29,30]$. No relationship between the frequency of polyp occurrence and the place participants live was found. The frequency of serrated polyp occurrence in patients who took part in a screening colonoscopy aged 40-49 with a history of abdominal cancer in the family and those aged 50-59 or 60-65 did not demonstrate any statistically significant difference. The data indicate that the au-

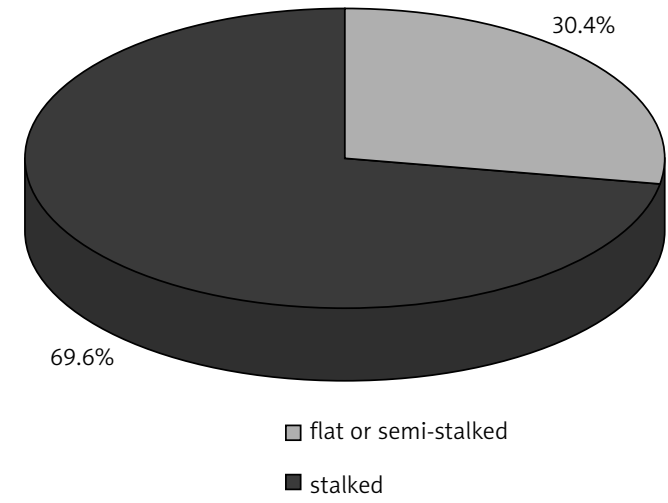

Fig. 8. Shape of the serrated polyps

thors of the Polish Screening Program took the appropriate decision to start screening colonoscopies in the group with a history of abdominal cancer in the family aged 40 and more [31]. Between 30 and $45 \%$ of CRC cases indicate a so-called familial aggregation that does not suggest particular mutations, but only the incidence of that type of malignant tumor in the family [32]. The screening colonoscopies performed in our center are characterized by their high quality, which is indicated by polyp removal in $25.9 \%$ of patients and cecal intubation in $92.2 \%$ [26]. The parameters of screening colonoscopy quality achieved by the team of doctor and nurses together with a very well or well-cleansed large intestine in $96 \%$ of cases are the basic factors that facilitated the detection, macroscopic evaluation, removal, and then the histopathological evaluation of the serrated polyps removed after polypectomy [15, 33, 34]. This type of polyp constitutes a heterogeneous group of abnormalities detected in the large intestine, among which hyperplastic polyps, or more 'advanced' adenomas such as traditional serrated adenomas, mixed serrated polyps or flat serrated polyps, are included $[6,35]$. The results of our analysis confirm the observations of other researchers who think that serrated polyps are more often found in the distal part of the large intestine; however, in our material every sixth serrated polyp was localized only in the proximal part of the large intestine, and a similar

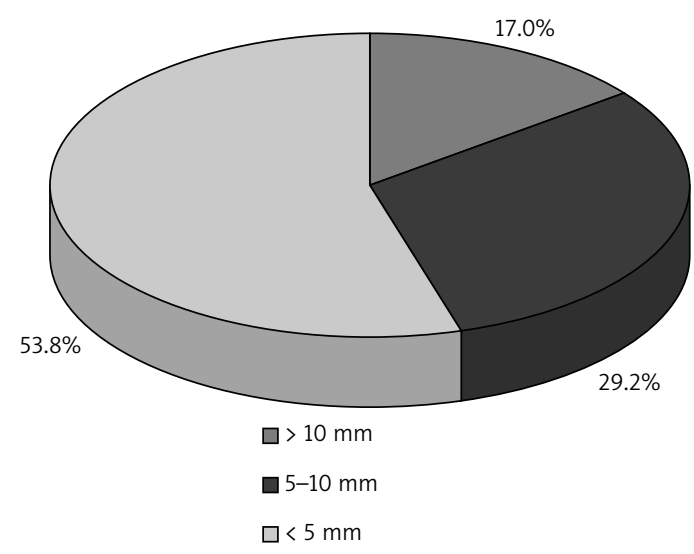

Fig. 9. Diameter of the serrated polyps 
Table 1. Diameter of serrated polyps in relation to gender

$\begin{array}{rlrl}\text { Diameter of serrated polyps } & \text { Women with serrated polyps }(n=883) & \text { Men with serrated polyps }(n=559) \\ & <5 \mathrm{~mm} & 15 & 33 \\ 5 & -10 \mathrm{~mm} & 15 & 35^{*} \\ > & 10 \mathrm{~mm} & 154^{*}\end{array}$

*statistically significant difference, $p<0.05$ (exact Fisher test)

number occurred simultaneously in the distal and proximal parts [36]. This also concerns the size of the removed serrated polyps. In the material from our analysis smaller polyps sized below $5 \mathrm{~mm}$ and between 5 and $10 \mathrm{~mm}$ predominated $[8,37]$. However, $17 \%$ of patients had polyps larger than $1 \mathrm{~cm}$, including one person with a polyp of about $5 \mathrm{~cm}$ located in the transverse colon. The results of the analysis, similar to other researchers' findings, indicate that in a significant percentage of people hyperplastic polyps, because of their size, must be removed under hospital conditions and that larger polyps are often accompanied by a multiplicity of polyps [38]. The results of our evaluation concerning one of the typical features of polyps, their stalk, are also similar to the results of other researchers. The serrated polyps removed through endoscopy were most often semi-stalked or flat and only $30 \%$ of the detected serrated polyps were stalked [8, 37]. Similar to other research results, in our screening colonoscopy material, among the serrated polyps the most frequent, i.e. in two thirds of the patients, were hyperplastic polyps. Traditional serrated adenomas occurred in one third of the patients and in 10 patients both histopathological types of serrated polyps occurred simultaneously. Within that group of polyps, 'advanced' serrated polyps occur less frequently in the large intestine $[8,16,35]$. Among the 171 people with serrated polyps, there were three cases when polyps which, according to the histopathological classification of large intestine polyps by the WHO, could be classified as mixed ones were removed. In all cases they were polyps characterized by the following: a size greater than $1 \mathrm{~cm}$, two of them had a clear stalk, and they occurred simultaneously with other polyps in the large intestine both in the distal and proximal parts. Two of the polyps had a hyperplastic and tubular structure and one had a hyperplastic and villous structure $[3,9,16]$. Burt and Samowits suggest that two forms may be distinguished in hyperplastic polyposis syndrome. One of them is composed of small, multiple polyps with a small risk of malignant transformation, while the other, called 'serrated adenomatous polyposis', is composed of large serrated polyps, other so-called 'advanced' serrated polyps and conventional adenomas. The characteristic feature of serrated adenomatous polyposis is a significant risk of CRC development [39]. In two patients the simultaneous presence of multiple serrated polyps in the distal and proximal parts, conventional adenomas and cancers (in one case located in the rectum and in the other in the transverse colon) was detected. It is also worth noting that two pathogenetic ways of colorectal cancer development may be present in one person, i.e. classical carcinogenesis as a process of the dysplastic foci of aberrant crypts changing through adenoma into cancer, and an alternative from aberrant crypt foci through serrated adenoma into cancer $[4,8,40]$. This alternative way of leading from 'aberrant crypt foci' through a serrated adenoma into cancer is less common than the conventional carcinogenesis in the large intestine, which has been recognized for several dozen years and occurs in between $15 \%$ and $35 \%$ of cases of sporadic large intestine cancer development [4, 6].

In conclusion, serrated polyps constitute a frequent, and very frequent among removed polyps, abnormality detected during screening colonoscopy. Hyperplastic polyps, polyps smaller than $1 \mathrm{~cm}$, without a stalk, multiple, located in the distal part of the large intestine, occurring in men or in patients with a history of abdominal (gastric, hepatic or colorectal) cancer in a first-degree relative are more frequently detected during screening colonoscopies. Cecum intubation and the well or very well-cleansed large intestine facilitated detection and removal of polyps. Where the patient lives and age had no influence on serrated polyp detection. Occasionally, serrated polyps had a mixed histopathological structure typical of both conventional adenomas and serrated polyps. Two cases of simultaneous 'serrated adenomatous polyposis' and CRC presence were detected.

The Screening Program for Early Colorectal Cancer Detection was funded by the Polish Ministry of Health.

Authors declare no conflict of interests.

\section{References}

1. Muto T, Bussey HJ, Morson BC. The evolution of cancer of the colon and rectum. Cancer 1975; 36: 2251-70.

2. Winter PC, Hickey G, Fletcher H. Epigenetics and chromatin modifications. In: Winter PC, Hickey G, Fletcher H (eds.). Short lectures. Genetics. PWN, Warsaw 2003; 374-81.

3. Hamilton SR, Aaltonen LA (eds.). World Health Organisation Classification of Tumours. Pathology and Genetics of Tumours of the Digestive Tract. IARC Press, Lyon 2000.

4. Jass JR, Baker K, Zlobec I, Higuchi T, Barker M, Buchanan D, Young J. Advanced colorectal polyps with the molecular and morphological features of serrated polyps and adenomas: concept of a fusion pathway to colorectal cancer. Histopathology 2006; 49: 121-31.

5. Han Y, Zhou ZY. Clinical features and molecular alterations of traditional serrated adenoma in sporadic colorectal carcinogenesis. J Dig Dis 2011; 12: 193-8.

6. Snover DC. Update on the serrated pathway to colorectal carcinoma. Hum Pathol 2011; 42: 1-10.

7. Waniczek D, Śnietura M, Młynarczyk-Liszka J, Pigłowski W, Kopeć A, Lange D, Rudzki M, Arendt J. PTEN expression profiles in colorectal adenocarcinoma and its precancerous lesions. Pol J Pathol 2013; 64: 15-20. 
8. Orłowska J, Kiedrowski M. Serrated adenomas, hyperplastic polyposis and colorectal cancer. Progress in Medical Science 2009; 2 111-7.

9. Torlakovic E, Skovlund E, Snover DC, Torlakovic G, Nesland JM. Morphologic reappraisal of serrated colorectal polyps. Am J Surg Path 2003; 27: 65-81.

10. Mäkinen MJ, George SM, Jernvall P, Mäkelä J, Vihko P, Karttunen TJ. Colorectal carcinoma associated with serrated adenoma prevalence, histologic features and prognosis. J Pathol 2001; 193: 286-94.

11. Lambert R, O’Brien MJ, Jaromillo E, Vieth M. The serrated pathway to colorectal cancer. World Gastroenterology News 2009; 14: 5-10.

12. Fujita K, Yamamoto H, Matsumoto T, et al. Sessile serrated ade noma with early neoplastic progression: a clinicopathologic and molecular study. Am J Surg Pathol 2011; 35: 295-304.

13. Żelazowski MJ, Bednarek AK. The state of contemporary molecular diagnostics of colorectal cancer. Wspolczesna Onkol 2011; 15: 229-33.

14. Snover DC. Sessile serrated adenoma/polyp of the large intestine: a potentially aggressive lesion in need of a new screening strategy. Dis Colon Rectum 2011; 54: 1205-6.

15. Sweetser S, Smyrk TC, Sugumar A. Serrated polyps: critical precursors to colorectal cancer. Expert Rev Gastroenterol Hepatol 2011; 5: 627-35.

16. Farris AB, Misdraji J, Srivastava A, Muzikansky A, Deshpande V, Lauwers GY, Mino-Kenudson M. Sessile serrated adenoma. Challenging discrimination from other serrated colonic polyps. Am J Surg Pathol 2008; 32: 30-5.

17. Williams GT, Arthur JF, Bussey HJ, Morson BC. Metaplastic polyps and polyposis of the colorectum. Histopathology 1980; 4: 155-70.

18. Jass JR. Classification of colorectal cancer based on correlation of clinical, morphological and molecular features. Histopathology 2007; 50: 113-30.

19. Buda A, De Bona M, Dotti I, et al. Prevalence of different subtypes of serrated polyps and risk of synchronous advanced colorectal neoplasia in average-risk population undergoing first-time colonoscopy. Clin Transl Gastroenterol 2012; 3: e6.

20. Peterlejtner T, Zdrojewski M, Firkowski P, Kwiasowsk R, Wojtowicz $Ł$, Buczyńska E, Szewczyk T. Effectiveness and safety of colonoscopic polypectomy. Pol Ann Med 2009; 16: 94-102.

21. Wallace K, Grau MV, Ahnen D, et al. The association of lifestyle and dietary factors with the risk for serrated polyps of the colorectum. Cancer Epidemiol Biomarkers Prev 2009; 18: 2310-17.

22. Rex DK, Petrini JL, Baron TH, et al. Quality of indicators for colonoscopy. Am J Gastroenterol 2006; 101: 873-85.

23. Fenoglio-Preiser CM, Lantz PE, Listrom MB, Davis M, Rilke FO. Pol yposis. Gastrointestinal Pathology. An Atlas and Text. Raven Press, New York 1989

24. Jørgensen H, Mogensen AM, Svendsen LB. Hyperplastic polyposis of the large bowel: three cases and a review of the literature. Scand J Gastroenterol 1996; 31: 825-30.

25. Landis SH, Murray T, Bolden S, Wingo PA. Cancer statistics 1998. CA Cancer J Clin 1998; 48: 6-29.

26. Mierzwa T, Windorbska W, Turczyn B, Jańczak R. Malignant neoplasm incidence in the Kujawsko-Pomorskie Province in 2008. Oncology Center, Prof. F. Łukaszczyk Memorial Hospital in Bydgoszcz; Bydgoszcz 2010.

27. Mierzwa T, Windorbska W, Turczyn B, Jańczak R. Malignant neoplasm incidence in the Kujawsko-Pomorskie Province in 2001 2005]. Oncology Center, Prof. F. Łukaszczyk Memorial Hospital in Bydgoszcz; Bydgoszcz 2007.

28. Świątkowski M, Meder A, Sobczyński L, Koza J, Szamocka M, Brudny J, Korenkiewicz J. Adenomas detected during screening colonoscopies in the years 2000-2009. Prz Gastroenterol 2012; 7 : 299-305.
29. Świątkowski M, Meder A, Sobczyński L, Koza J, Szamocka M, Brudny J. The screening program for the early colorectal cancer detection performed at the Gastroenterology Department of Nicolaus Copernicus University in Torun Collegium Medicum in Bydgoszcz in 2000-2009. Pol J Gastroenterol 2010; 17: 410-5.

30. Homa K, Safranow K, Brzosko M, Marlicz K. The evaluation of usefulness and tolerance of screening colonoscopy programmes in relation to selected demographic factors. Pol J Gastroenterol 2005; 12: 499-503.

31. Regula J, Rupinski M, Kraszewska E, Polkowski M, Pachlewski J, Orlowska J, Nowacki MP, Butruk E. Colonoscopy in colorectal-cancer screening for detection of advanced neoplasia. N Engl J Med 2006; 366: 1863-72.

32. Kotynia J, Małecka-Panas E. Chemoprevention of colorectal cancer. Pol J Gastroenterol 2006; 13: 53-8.

33. Kotowski B, Kamiński MF, Rupiński M, et al. Analysis of colonoscopy quality in all-Polish Program of Screening Examinations for Early Colorectal Cancer Detection. Gastroenterol Klin 2009; 1: 45-53.

34. Patel SG, Ahnen DJ. Isn't it time to stop talking about colonoscopy quality and start doing something about it? Dig Dis Sci 2011; 56: 2776-9.

35. Higuchi T, Sugihara K, Jass JR. Demographic and pathological characteristics of serrated polyps of colorectum. Histopathology 2005; 47: 32-40.

36. Lewis JD, Ng K, Hung KE, Bilker WB, Berlin JA, Brensinger C, Rustgi AK. Detection of proximal adenomatous polyps with screening sigmoidoscopy: a systematic review and meta-analysis of screening colonoscopy. Arch Intern Med 2003; 163: 413-20.

37. O’Brien MJ, Winawer SJ, Zauber AG, et al. The National Polyp Study. Patient and polyp characteristics associated with high-grade dysplasia in colorectal adenomas. Gastroenterology 1990; 98: 371-9.

38. Guillem JG, Smith AJ, Puig-La Calle J, Ruo L. Gastrointestinal polyposis syndromes. Curr Probl Surg 1999; 36: 219-23.

39. Burt RW, Samowits WS. Serrated adenomatous polyposis: a new syndrome? Gastroenterology 1996; 110: 950-2.

40. Vu HT, Lopez R, Bennett A, Burke CA. Individuals with sessile serrated polyps express an aggressive colorectal phenotype. Dis Colon Rectum 2011; 54: 1216-23.

\section{Address for correspondence}

\section{Jarosław Koza}

Department of Gastroenterology, Vascular and Internal Diseases Ludwik Rydygier Collegium Medicum in Bydgoszcz

Ujejskiego 75

85-168 Bydgoszcz, Poland

e-mail: jarek koza@wp.pl

Submitted: 18.12 .2012

Accepted: $\quad 16.07 .2013$ 